\title{
Empowering Language: Lenses of Knowing, Being and Doing
}

\author{
JOANNA WILLIAMSON \\ Faculty of Education and Social Work, University of Auckland \\ HELEN HEDGES \\ Faculty of Education and Social Work, University of Auckland
}

\begin{abstract}
Mana, a notion reflecting empowerment, is a central concept in te ao Māori, the world views of the indigenous culture in Aotearoa New Zealand. Mana forms a key component within Aotearoa New Zealand's bicultural early childhood curriculum Te Whäriki and Māori early childhood assessment framework Te Whatu Pōkeka. Lenses of these culturally responsive frameworks are applied to verbal interactions amongst Indigenous Canadian children playing in school. Play was utilized to empower the children's ideas and oral language towards richer storytelling. We argue that it is important for all teachers to consider and work with local and culturally responsive frameworks relevant to their context to empower children's voices.
\end{abstract}

\section{Introduction}

Empowering children's learning is vital across cultural contexts. This article examines possibilities for empowering Indigenous Canadian children's language through the use of play in primary/elementary school. We do so using aspects of Aotearoa New Zealand's bicultural and bilingual early childhood curriculum framework, Te Whäriki (Ministry of Education [MOE], 1996), and ideas from the corresponding early childhood narrative assessment framework for Māori children, Te Whatu Pōkeka (Ministry of Education [MOE], 2009). Our intention is to provoke the repositioning of indigenous ways of knowing across contexts.

We were invited to link our work on play and curriculum in Aotearoa New Zealand to data from a project in Ontario, Canada, called Northern Oral Language and Writing through Play (NOW Play). The NOW Play emphasis is on ways oral language might be empowered and strengthened through play-based learning. This project is working with a number of primary schools in remote and rural communities, some of which include Indigenous children. One premise of the project is to introduce more play into teaching programmes in the first years of schooling to foster richer oral language exchanges between children and teachers.

Our challenge was to apply ideas from our curriculum context in a different cultural context. This article examines excerpts of data we were provided with of children at play. We use lenses for analysis that may be responsive to Indigenous children's ways of knowing and being. Like many non-Indigenous teachers working with Indigenous children, we too are grappling with what it means in practice to work with culturally sustaining pedagogy (Paris, 2012). Our intention, therefore, is to highlight some key concepts of our 
early-years frameworks in ways that might be considered across cultural contexts in locally responsive ways.

Aotearoa New Zealand is recognised as standing at the forefront of culturally responsive education due to its twenty-year history of working to implement a bicultural early childhood curriculum framework underpinned by te ao Māori, sociocultural and ecological theories of learning and development (Ritchie \& Buzzelli, 2012), and prioritising attention to Māori learners in primary and secondary education (Bishop, Berryman, Wearmouth, Peter, \& Clapham, 2012). However, paradigmatic shifts are slow to evolve. As teachers and researchers we tend to fall back on enacting the world we know, and therefore may encounter difficulty applying an indigenous lens when it is not recognized readily within existing practices. These difficulties may include recognizing different communication styles and how Indigenous children may respond to, or resist, more westernized teaching and assessment approaches.

Shifts require on-going learning in teachers' professional knowledge and practice, for example, in using assessment for learning in culturally appropriate ways. This may be particularly the case in locating ways that are responsive to children's embodied ways of knowing or ways responsive to family knowledge. In the specific context of Canada, Peterson, McIntyre and Forsyth (2016) are concerned that teachers of Indigenous children "need to learn more about bridging children's home and school cultures and languages" ( $p$. 11) in an effort to recognise and value the knowledge that Indigenous children bring to their learning.

Allen (2014) comments on the "urgent necessity" (p. 1) of teachers having culturally relevant assessment practices for Indigenous children in Canada, particularly in the area of language assessment, highlighting that typically Westernized assessment tools are employed which do not recognize the linguistic and cultural diversity of Indigenous children's language. For example, she identifies that questioning techniques may be different between indigenous and non-indigenous communities, and that Indigenous children may be quiet as a sign of respect, or may feel shy and less inclined to participate until they fully comprehend what is expected of them. In this way play can be a useful context to encourage participation in learning and for assessing understanding. Here the inseparable relationship between language and culture, and teachers' recognition of this, is exemplified. Elsherief (2016) similarly problematizes culturally responsive teaching and learning because culture is dynamic, and not a fixed way of knowing and being. Therefore, she argues that to teach and learn with children in culturally responsive ways teachers need a deep understanding of the "nuanced ways in which our students internalize and 'do' culture" (p. 3). These challenges highlight the importance of working to understand and apply frameworks that are informed by and designed for Indigenous children to better enable us to work in ways that are culturally sustaining (Paris, 2012). We engage with Aotearoa New Zealand curriculum and assessment frameworks in this paper to provoke thinking in the Canadian context with regard to Indigenous children.

\section{Early Childhood Education in Aotearoa New Zealand}

Aotearoa translates as "land of the long white cloud" and is the Māori name for New Zealand. It originates from the words of the first Māori navigators to arrive, upon seeing a long cloud indicating a possible land mass on the horizon. As Māori is now an official language the addition of Aotearoa to the name New Zealand recognises a commitment to fore fronting tangata whenua (the people of the land), and the founding 
treaty. Aotearoa New Zealand is a nation founded on a treaty partnership-Te Tiriti o Waitangi, The Treaty of Waitangi. This treaty was signed by representatives of the British Crown and many Māori chiefs of Aotearoa in 1840. Honouring Te Tiriti o Waitangi as the founding document of partnership between Māori and immigrant settlers has been fraught over the years, and has more recently been approached from perspectives of settling historic claims. Correspondingly, and following patterns similar to Canada and other post-colonial nations around the world, the Indigenous population of Aotearoa New Zealand is overrepresented in statistics for poorer educational and health outcomes, higher rates of offending and imprisonment, and lower-socio-economic status. These societal realities for Indigenous populations reinforce the importance of education systems being relevant and responsive for Indigenous children and for teachers to explore more effective ways of working with culturally responsive curriculum and assessment.

As non-Māori authors we acknowledge that we cannot speak with authority about Māori concepts and values. However, as partners to the Treaty of Waitangi in Aotearoa New Zealand non-Māori early childhood teachers take responsibility to learn about and uphold the bicultural intentions of our curriculum framework. We also work towards recognising Māori ways of knowing, being and doing as we work with lenses of culturally responsive curriculum design and assessment to empower Indigenous children's play and language. For the purposes of this paper we selected the curriculum lenses of Whakamana, the empowerment principle, and Mana Reo, the communication strand of Te Whāriki (MOE,1996), alongside the concept of whakapapa, represented as the layered lenses of knowing, being and doing within the Māori assessment framework Te Whatu Pōkeka (MOE, 2009). We explain these te ao Māori concepts shortly, offering our interpretations and thoughts in the knowledge these may be partial and still in development. Te Whatu Pōkeka was developed with two groups in mind, firstly Māori early childhood services, and secondly as a support resource for all early childhood services across Aotearoa New Zealand to inform more culturally responsive assessment practices for Māori children in mainstream services. In this way it is also intended for non-Māori teachers to work with (Rameka, 2007).

We encourage other non-Indigenous researchers and teachers to take up similar challenges and responsibilities in their contexts, that is, seek local and relevant concepts for responsive curriculum and assessment. We reiterate that our interpretations are subjective and somewhat limited, nor are we embedded in the Canadian context. Our intention is to provoke thinking about the potential applicability of local culturally responsive frameworks in other contexts.

\section{Te Whäriki: Early Childhood Curriculum}

As the first bicultural curriculum document in Aotearoa New Zealand, the national early childhood curriculum framework Te Whäriki (MOE, 1996) became a flagship document locally and internationally. Its bilingual text, structure and interwoven principles (Whakamana - Empowerment, Kotahitanga - Holistic Development, Tangata Whenua Family and Community and Ngä Hononga - Relationships) and strands (Mana Atua - Well Being, Mana Whenua - Belonging, Whānau Tangata - Contribution, Mana Reo Communication, and Mana Aotūroa - Exploration) weave together to reflect partnership and reciprocity. "In early childhood settings, all children should be given the opportunity to develop knowledge and an understanding of the cultural heritages of both partners to Te 
Tiriti o Waitangi. The curriculum reflects this partnership in text and structure" (p. 9). Te Whāriki translates as "woven mat", a metaphor for weaving a responsive curriculum for all to stand on, to belong, and be empowered. One of the Māori co-developers of the curriculum stated:

Te Whäriki recognises my right to choose, and your right to choose. It encourages the transmission of my cultural values, my language and tikanga, and your cultural values, your language and customs. It validates my belief systems and your belief systems. (Reedy, 2013, p. 52)

Early childhood education, understood internationally as birth to 8 years, is the beginning of a child's journey into education outside the home, therefore teachers and researchers cannot underestimate the importance of Indigenous children experiencing curriculum and assessment that empowers their identity and values, and upholds their rights. Empowering children's identity development begins in the early years and extends into formal schooling contexts. The following concepts of te ao Māori (the Māori world) embedded within our national early-years curriculum and assessment documents $T e$ Whäriki and Te Whatu Pōkeka are particularly relevant to Māori identity and values in this paper.

Te ao Māori values whakapapa - a layered knowing of who we are, where and who we have come from; what is embodied in our past, present and future ways knowing and being. "Ko wai koe? Nā wai koe? I ahu mai koe I hea? Who are you? From whom are you? Where have you come from?" (MOE, 2009, p. 50). In Western world views this concept is similarly expressed through a family tree but is limited to ancestors rather than incorporating place as spiritual and physical links to the land and gods. It is these multiple layers of identity and connection that create the layers of knowing, being and doing. Whakapapa is a traditional form of knowing that underpins every aspect of te ao Māori.

Whakapapa provides a continuum of life from the spiritual world to the physical world, from the creation of the universe to people past, present and future. While whakapapa permits Māori to trace descent through to past generations, it also allows movement and growth into the future. (Rameka, 2012, p. 33)

As educators and treaty partners in Aotearoa New Zealand, we acknowledge this Māori valuing of identity and connection. Conceptually, whakapapa may also speak of non-Māori knowing and being, our past, present and future, our connections with time and place, how we came to be here, and our right to be here as treaty partners. In viewing our world this way, we challenge our Westernized world views as we 'look' through these other lenses.

\section{Mana and Mana Reo - Empowering Languages}

"Mana can be translated as 'prestige' or 'power" (Rameka, 2007, p. 129), and is central to being empowered as an individual. Mana is a cornerstone of Te Whāriki, ensuring that

the learner is empowered in every possible way. ...The child is nurtured in the knowledge that they are loved and respected; that their physical, mental, 
spiritual, and emotional strength will build mana, influence, and control; that having mana is the enabling and empowering tool to controlling their own destiny. (Reedy, 2013, p. 47)

We question how empowering children might happen if traditional and embodied ways of knowing are not recognized through relevant cultural lenses. Empowered children are in control of their learning and the direction of their learning. In Aotearoa New Zealand's early childhood education context this often translates as the child leading their play, through embodying their ways of knowing in their play and this being recognized and valued. Mana is central to, and named in, all five strands of Te Whäriki.

In this article we highlight one strand: Mana Reo: Communication. Mana Reo empowers children's languages through the explanation: "The languages and symbols of their own and other cultures are promoted and protected" (MOE, 1996, p. 72). The goals for this strand are for children to:

experience an environment where they: develop non-verbal communication skills for a range of purposes; develop verbal communication skills for a range of purposes; experience the stories and symbols of their own and other cultures; and, discover and develop different ways to be creative and expressive. (p. 72)

Suggested learning outcomes include experience with developing stories, an ability to be creative and expressive through play and storytelling, using language for increasingly complex purposes, showing a playful interest in sounds and words, and the expectation that verbal communication will be a source of delight and amusement. Examples of experiences for young children include opportunities for sustained conversations and to take the initiative in such conversations, opportunities for play and having fun with words, and talking about topics that encourage complex language.

\section{Whakamana-Empowerment}

The overarching curriculum principle of Whakamana is interwoven with Mana Reo. Whaka may be translated as "to enable", "Whakamana in the context of education relates to the process of empowering the child to learn and grow" (Rameka, 2007, p. 129). Te Whāriki emphasises the interconnections between Empowerment and Communication and the three other principles of the framework:

[T] he communication strand is grounded particularly in the principle of Empowerment. Communication is vital for children to be able to contribute their strengths and interests, to find out what they want to know, and to take increasing responsibility for their own learning and care. Experiences in this strand also help to build Relationships, as children develop the "give and take" of communication and learning and have opportunities to work effectively with others in ways which have an impact on their environment. The ability to communicate increases their enjoyment and involvement with Family and Community, helping them to make sense of, and participate in, the wider cultural and social world. Communication reinforces the child's 
Holistic Development of a concept of self, enhancing their recognition of their spiritual dimension and the contribution of their heritage and environment to their own lives. (MOE, 1996, p. 72)

This principle is identified as evident when children show an enhanced sense of self-worth, identity, confidence and enjoyment, contribute their own special strengths and interests, and understand their own ways of learning and being creative.

In relation to the Indigenous Canadian context, the concept of whakamana is relevant to the cultural and linguistic diversity and funds of knowledge (González, Moll, \& Amanti, 2005) that Indigenous children bring with them into early childhood centres and schools. Both Te Whāriki and Te Whatu Pōkeka align theoretically with the concept of funds of knowledge. While not unproblematic (Hedges, 2015), within this concept, children's ways of knowing and being embedded in everyday routines, practices, and activities in their family, community, and cultural lives are recognised and valued in their learning and assessment. Through this lens both content and process - that is, the relationships in which knowledge building happens - are reflected in the context of education settings to include wider family, peers both in and out of centre settings, and cultural knowledge such as traditional and contemporary culture.

If children's ways of communicating, and the rich social, cultural, and linguistic practices learned in homes and communities are not recognized within educational settings, children are likely to feel disempowered. In the context of Canada, it has been argued that "Aboriginal children [may be] erroneously identified with language, speech, and learning exceptionalities [i.e., difficulties] because educators lack knowledge and training in language variation, students' cultural and linguistic backgrounds, and the challenges inherent in learning to use standard English" (Peltier, 2010, p. 139, cited in Peterson et al., 2016, p. 13). We suggest that the curriculum principle of Whakamana, and the strand of Mana Reo provide examples of lenses for teachers to notice, recognize, and respond to student's linguistic and cultural capital as embodied ways of knowing and evident in the variety of ways they use language and express their ideas and creativity.

\section{Assessment framework for Māori children: Te Whatu Pōkeka}

Upholding a child's mana is illustrated in many ways, including when assessing Indigenous children through a relevant and culturally sustaining assessment framework. "Assessment for Māori must therefore acknowledge, respect, and protect each child's mana and further promote and encourage its growth and development (Rameka, 2007, p. 138). In keeping with Aotearoa New Zealand's bicultural curriculum framework, an approach to assessment that affirms whakapapa, holism, and interconnectedness was developed: $T e$ Whatu Pōkeka (MOE, 2009), an indigenous assessment framework (Walker, 2008).

Te Whatu Pōkeka was developed by Māori early childhood academics. It incorporated narrative assessment, appropriate given the oral traditions of story-telling valued by Māori, and in alignment with Aotearoa New Zealand's dominant narrative assessment framework - learning stories (Carr, 2001; Carr \& Lee, 2012), where the lenses of assessment are predominantly framed through the notion of dispositions. Te Whatu Pōkeka emphasises te ao Māori lenses and dispositions for learning, where Māori ways of knowing, being, and doing are at the heart of assessment. Assessment through te ao Māori lenses values the importance of embodied ways of knowing and being, immersion in cultural practices, and how these are embedded in ways of doing that may be viewed as 
dispositions for learning and teaching. For example, the valued qualities inherent in the demigods of Māori myths and legends highlight differences with what might be valued in a Western assessment paradigm. In te ao Māori resourceful qualities like mischievousness and cunning are valued alongside dispositions such as perseverance, involvement, and the multiple ways a child might be curious. Thus both Māori and non-Māori ways of knowing and being might be highlighted in bicultural assessment narratives.

\section{Mohiotanga, Matauranga, and Maramatanga: Ways of knowing, being, and doing}

Māori ways of knowing, being, and doing are three interconnected layers of whakapapa which frame the lenses of assessment practices for Māori children. In Te Whatu Pōkeka they are as follows: Mohiotanga, ways of knowing as understandings of the world(s) and relationships within them. Through this lens, what a child already knows and what they bring with them highlights new beginnings, new knowledge, and new discoveries. This perspective takes into account spiritual and ancestral knowings as well as more tangible understandings and ways that non-Indigenous educators might identify with. Matauranga, ways of being as ways in which children act upon and within their world(s); these may be constructs of the child, family, and teacher. This is a time of growth, a phase of increasing potential, negotiation, challenge, and apprehension when dealing with new ideas and new learning. Maramatanga, ways of doing as the ways in which children learn and teachers learn, plan, teach, and assess within their world(s). (MOE, 2009). Maramatanga highlights uniqueness and identity and the process of coming to understand new knowledge. It is a space of enlightenment, realisation, and clarification for children and teachers.

While acknowledging that Te Whatu Pōkeka is built on theorizing about indigenous framings for curriculum and assessment in the context of Aotearoa New Zealand, we argue that these kinds of conceptual lenses may be considered for application to curriculum and assessment for Indigenous children across cultural contexts. In the case of this paper, the concepts embedded in Te Whatu Pōkeka may be 're-lensed' in ways that are relevant to the Canadian context. Responsive frameworks that recognize and create space for children to draw on the funds of knowledge (González et al., 2005) from their homes and communities enables Indigenous children to find and make new meaning in classroom activities. Referring specifically to Canada, Weenie (2008) notes that

[T]he landscape of Aboriginal curriculum involves the colonial history, worldviews, philosophies, languages, cultures, stories, songs, literature, art, spirituality, ceremonies and ethos of Aboriginal people. These are the 'things' or objects that make up our embodied ways of knowing. They form a body of knowledge that represents the order of things in the worlds we live and work in. (p. 551-552)

We turn now to consideration of the NOW Play project as we analyse data through these concepts. As researchers in a different context we were provided with a selection of conversation transcripts, with additional field work observation notes of context and actions, of children at play to select from to analyse using lenses from our own cultural contexts. 


\section{Project rationale and methods}

The NOW Play project has been developed in indigenous and remote communities in Northern Canada. Its aim is to improve the oral language and writing capabilities of early school learners. The project has adopted play-based teaching approaches for part of the school day for a range of reasons that include: (a) To provide playful scenarios and opportunities to increase children's oral language; (b) That Indigenous children tend to respond best to playful tasks during language assessment rather than more standardized Western assessment tools (Allen, 2014; Peterson et al., 2016). In the project play and oral language are focussed on as mechanisms which might lead to subsequent richer narrative story-telling and later writing. NOW Play incorporates a number of methods; one of which was recording play-based conversational exchanges in classrooms.

We selected a transcript of dialogue of three Grade 1 (aged 6-7 years) Indigenous children playing with blocks alongside their teacher. The culturally responsive lenses outlined above are applied for consideration of planning and assessing the empowerment of children's language through play, with the aim of provoking wider exploration of what can be drawn on to acknowledge the unique and embodied ways children play and interact across contexts. We acknowledge our interpretations as partial as we do not know the children, the teacher, or much about the context under analysis. Likewise, without knowing the ancestral ways of the First Nations, Métis and Inuit peoples, we cannot draw conclusions; our goal is to provoke ways of viewing learning and assessment from our context that might encourage responsiveness for Indigenous children across cultural contexts.

\section{Analysis and Interpretation of Concepts}

We highlight children's - and at times the teacher's - embodied ways of knowing, being, and doing within these three lenses, alongside te ao Māori curriculum concepts of mana and whakapapa. The curriculum principle of Whakamana, Empowerment; the strand of Mana Reo, Communication; empowering language, and the theoretically aligned Western paradigm of social and cultural responsiveness, funds of knowledge (González et al., 2005) are also considered. These concepts are interrelated and inseparable, as can be seen in the analysis of excerpts. They weave together to illustrate the embodied ways the children and the teacher talk, play, and story-build together. Through our shared analysis of the dialogue, we located excerpts of the transcript in which we could explore considerations for teachers using play and narrative as ways to empower pathways for richer language and literacy experiences. The importance of teachers working with young Indigenous children to recognise the children's embodied ways of knowing, being, and doing will be discussed.

In the following analysis, two of the three children - Cara and Alexandra- draw richly from their wider lives outside of the classroom to share and make new meaning using their own and each other's ideas as they build complex imaginary narrative. When the teacher responds playfully to the children's ways of knowing and being, joining them in shared thinking and dialogue, the children respond enthusiastically by inviting her into their playful scenarios. In this way the teacher joins them reciprocally as both a co-storyteller and a learner. During these particular interactions the two children and the teacher learn from each other and together, drawing on each other's repertoires, and elaborating each other's stories. This might be seen as embodying culturally competent teaching and 
learning practices of being open to uncertainty and multiple truths through recognising other ways of knowing.

Excerpt 1 (Beginning of Transcript)

Transcript Interpretation of Concepts

Cara: A Veee.

Alexandra: Can help me with the teepee?

Teacher: Well you can ask.

Alexandra: The [teepee]

Teacher: [Cara] can help you with the teepee.

Alexandra: She's building her little teepee to be in a movie.

Cara: [Alexandra.]

Teacher: [A movie? ]

Teacher: You're building a movie? What are you building, Cara?

Cara: Nah.

Alexandra: She won't tell. It's a secret. Teacher: Oh I have to guess. Okay. Weren't the two of you going to build something together?

Teacher: Was that the idea, that you build things together? Is that how you do it?

Alexandra: We're making a [...] movie. Cara: Look I made a computer.

Alexandra: A stoney perk.

Teacher: Ahhhh. For a Story.

Alexandra: We're making a storybook for a wedding.

Teacher: I'm looking forward to reading your storybook later on.
Mana Reo: Empowered to

communicate and suggest ideas for a

story.

Ways of knowing: Drawing on real

world and local knowledge.

The teacher's way of being (i.e., her intention) appears to be encouraging

collaboration to generate shared story

building.

Funds of knowledge

Popular culture

Ways of being: Resistance to teacher trying to lead the play.

Whakamana: Leading own playactively resisting teacher's attempts to steer them towards specific construction to write about later.

Teacher still intent on encouraging collaboration and prompts accordingly.

Whakamana: The children take the lead, each in their own direction.

Child's way(s) of being clashes with teacher's way(s) of doing: Teacher is focused on the end product-story writing -rather than play and oral language. 
Alexandra: Puhpo bear came to my house to use the toilet.
Whakamana: Empowered to verbally resist questioning with cheekiness. Mana Reo: Knowing that words can amuse and delight, playing with language.

Ways of being: Resistance to teacher trying to lead the play.

These two children appear empowered to know what is expected of them in this playful classroom scenario. Mana Reo is evident as they work both overtly and covertly to ensure their play and their subsequent narrative is directed by them. Their ways of being are evident in their play: they both resist and invite the teacher to play in their storied world depending on how responsive she is to their ways and intentions. The teacher's ways of knowing and being are evident through her apparent understanding of what it is to teach while children play rather than teach within their play. Her strategizing for story and language elaboration illustrates that more playful and responsive interactions draw richer ideas, language and invitations from the children. Contrastingly, her attempts to 'teach' by questioning and prompting for problem solving and elaboration rather than playing along with the story results in the two children either ignoring her questions and prompts, disrupting with 'toilet' humour, or redirecting the conversation back to their own intentions. The interaction continues:

Excerpt 2

Transcript

Cara: I need-I'm homeless!

Teacher: Is that your story?

Cara: I'm home inside familyless.

Teacher: Oh! So but you've got a computer right here.

Cara: I GOT NO FAMILY AND NO HOME.

Teacher: No home. And. What are you building for yourself, since you have no home?

Alexandra: No she can live with me Cara: That's I Ka U.

Teacher: That's a good idea, you can move in with your friend.

\section{Interpretation of Concepts}

Teacher and child's ways of being: Teacher prompts for clarification and to extend story. Cara resists the teacher's prompts.

Funds of knowledge or imagination? Child raises poignant themes of being homeless and alone, and of running away, and seems intent on persisting with these ideas to drive the story.

Cara is not heard.

Whakamana: Raises voice to stress her idea in order to be heard.

Ways of being: Children are more responsive and generate more ideas when the teacher's suggestions and elaborations are more in tune with their play.

Ways of doing: The teacher begins to recognize the play as potential for elaboration and tries to join in a more playful way. 
Teacher: So now you have no place to go poor homeless girl. Your friend doesn't have a place to go either. Cara: We could make one. Alexandra: We could make a big one, like a big castle.

Alexandra: With a big door, where we could fit in there.

Alexandra: Cause we have a lotta blocks.

Teacher: We do. We could make a lot of castles and a big castle with those blocks.

Alexandra: Oh no, you be-you be this guy. And you get in the car.

Teacher: Where are we going?

Alexandra: We are going on blue one.

Teacher: I'm gonna go right here? ...

Alexandra: Here we go!

Cara: Wait for-don't forget me.

Teacher: Oh no, we left our friend behind.

Teacher: We better back up.

Cara: Ahhh. My buddies.
Mana Reo: empowered language; being

creative and expressive.

Ways of being: The children are responsive to her ideas now and build on them using their language and narrative knowledge.

Fantasy and reality; imagination and creativity

Ways of doing: The teacher is now playing along as a character in the drama and is no longer resisted, but invited into the play. Ways of doing: shared thinking and working together. The narrative flows and builds on itself.

Ways of doing: Teacher is playful; children are inclusive.

This dialogue shows the same two children continuing to story their creative ideas. Their language and thinking is empowered as they work with each other to negotiate plot lines. In the strand of Mana Reo this is defined as: "Language skills in real play, and problem solving contexts" and "language skills for increasingly complex purposes such as stating and asking others about intentions.... negotiating, predicting, planning, reasoning, guessing, storytelling" (MOE, 1996, p. 76). They actively choose collaboration or resistance to build on or shift the storyline according to their own agendas/ways of being. In their play they show confidence and competence to be involved, and Mana Reo are evident throughout the ways they believe in their ideas and they demonstrate knowledge of how to build, sustain, or disrupt a narrative. They appear empowered to resist the teacher's and each other's suggestions at times while also being competent in knowing about how to collaborate and share ideas.

Throughout their play the children link their own family and community experiences with popular culture and imagination to build and shift their stories into 
complex narratives. In this way reality and imagination combine and mediate rich thinking and talking, an important combination identified by Vygotsky (2004): "Imagination always builds using materials supplied by reality" (p. 14). The children encourage each other in these endeavours by both building on and rejecting suggestions and concepts. Again, the teacher's presence is less effective initially as she is intent on prompting for story building and collaboration. The two children demonstrate empowerment in their ways of knowing and being to lead their play. Later, the teacher opens up to new learning too as she shifts her ways of doing as a teacher to value the playful ideas the children bring. This playfulness is illustrated in the next excerpt.

\section{Excerpt 3 \\ Transcript \\ Cara: Mmmm mmm hydro mana. \\ Cara: Ahhhh. \\ Alexandra: You breaked the house! \\ Cara: I went to the house! \\ Alexandra: This is her. \\ Teacher: Okay. \\ Interpretation of Concepts \\ Mana Reo: playing with sounds and \\ words \\ Ways of doing: The teacher recognizes the children's disruption as a kind of story building and avoids negative or pacifying responses...}

Teacher: Where's the house? What happened to the house? I thought I was coming for a visit?

Cara: I crashed into it.

Teacher: Oh no! What did you crash in with?

Cara: Where to, where's the hammer?

Cara: My hou-

Cara: I broke the house. Hehe

Alexandra: That thing is-

Alexandra: A bada bada.

Cara: Ah! I blowed up again. Hahah!

Alexandra: Buuuugh.

Alexandra: Ay help me!

Cara: Look. Here's one of my missiles.

Cara: And it blowed up you.

Cara: Look. My missile. Blowed up you.
... in order to continue her presence and the story line

\begin{abstract}
Mana Reo: The children negotiate and collaborate over changing direction in the play. Mana Reo: playing with language
\end{abstract}

Ways of knowing: Drawing on popular culture, and fantasy and reality

Several times throughout the transcript these two children use destruction as a means of shifting storylines in the play as they grapple to take the lead from each other. They use karate chops, planes crashing, and missiles blowing things up-presumably drawing from popular culture and media based experiences. This playful combination of funds of 
knowledge and imagination through storying aspects of their own lives while incorporating fantasy through the suspension of disbelief are used throughout as ideas for developing the narrative. New ways of doing (i.e., teaching) includes the teacher recognising and responding without judgment to the children's ways of being for solving story crises or a need for plot redirection. Popular culture is often an important interest of children in terms of how they make meaning in ways that may lead them to examine and inquire into aspects of their own lives (Hedges, 2011). This imagination continues in the following excerpt.

\begin{tabular}{ll} 
Excerpt 4 & \\
\hline Transcript & Interpretation of Concepts \\
\hline Alexandra: Helka Taytha. Almost like in & $\begin{array}{l}\text { Funds of knowledge: popular culture, } \\
\text { movies }\end{array}$ \\
$\begin{array}{l}\text { Frozen. Like on Frozen. } \\
\text { Cara: You know. Let It Go. Let it Go! }\end{array}$ \\
$\begin{array}{l}\text { Cara: I can't hold it back Anymore! } \\
\text { Cara and Alexandra: Hehahaha. }\end{array}$ \\
$\begin{array}{l}\text { Cara: A can't hold and back Anymore! } \\
\text { Cara and Alexandra: Hehahaha. }\end{array}$ & Mana Reo: being expressive, song and \\
\end{tabular}

$\cdots$

Alexandra: Guess who is this thing. Mobly.

Teacher: Mobly?

Alexandra: Yeah.

Teacher: Where did you get name from?

Alexandra: Ahhh Jungle Book 2! Ehh this is the bench.

Mana Reo: understanding that books and stories (extrapolated to movies) can amuse, delight, illuminate, inform and excite

Cara: You look here's my-here's my back pack...cause I'm- cause I'm- CAUSE I'M

Funds of knowledge LEAVING THE TOWN.

Teacher: Where you heading there with the back pack?

Cara: Sioux-come.

Alexandra: Soup de soup to see her best buddies.

Teacher: Okay! So have a good time. Cara: Okay! Ahh. My back pack fell off. Alexandra: This is the water.

Teacher: Oh is there water around the castle?

Cara: I'm takin a boat.

Alexandra: You.

Cara: Stop pretending the bad guys are trying to chase me.

Mana Reo: being creative and expressive, drama and pretend play Mana Reo: a playful interest in sounds and words, using words to amuse and delight

Ways of doing: This is seen in both the children's and the teacher's recognition that the children resist attempts to be 'taught' solutions for their narrative crossroads.

Funds of knowledge: goodies and baddies 
Teacher: They're chasing you?

Cara: Yeah.

Teacher: Are you going to get away?

Cara: Yeah.

Teacher: Are you coming back to the castle Fantasy and reality

to get away or where are you going to get

away?

Cara: Uh....

Alexandra: She'll get away in Winnipeg to

hide.

Teacher: Winnipeg's a good place. Ways of knowing: Incorporating local

Alexandra: I'm driving.

places and driving across vast

landmasses

In this excerpt, the two children draw on their funds of knowledge and ways of knowingas they incorporate local language and landmarks, places, books, and movies. They reveal their familiarity with storying as they utilize the pervasive dichotomies of goodies and baddies, fantasy and reality while verbally reflecting aspects of everyday of family and societal life. Their vast array of collective experience is drawn from to create or disrupt new narrative, for example, running away, driving across the country, or visiting people in far off places, thus likely incorporating the real life experiences of travelling across the vast landmass of Canada. The shaped blocks become various means of escape for leaving home, and being homeless. Block constructions represent both reality and imagination: from tepee and cars for travelling, to castles with dragons and dungeons where bad guys are locked away. These two children draw richly from their accumulated ways of knowing, using the blocks as mediating tools across the reality-fantasy divide.

In their play and language, blocks become powerful, tangible, and abstract tools for storying their rich experiences and ways of knowing. As Weenie (2008) notes, "Aboriginal people came to know and understand their world through imaginative endeavour and this was most evident in the oral tradition" (p. 552). Through imaginative oral storytelling the children are creating and recreating complex narratives showing the "ability to be creative and expressive through a variety of activities such as pretend play, carpentry, storytelling, drama" (MOE, 1996, p. 80).

\section{Enhancing all children's mana and Mana Reo}

Alongside the richer interactions of these two children and their teacher we point out the actions and speech of a third child on the periphery of this play. Throughout this entire exchange, James makes minimal contribution to story building, and is acknowledged only occasionally by the other two children and the teacher. He rarely joins in the dialogue and largely remains outside of the play and the verbal narrative being constructed. The two interactions below are the only verbal contributions of James throughout the 21-minute play transcript. 
Excerpt 5

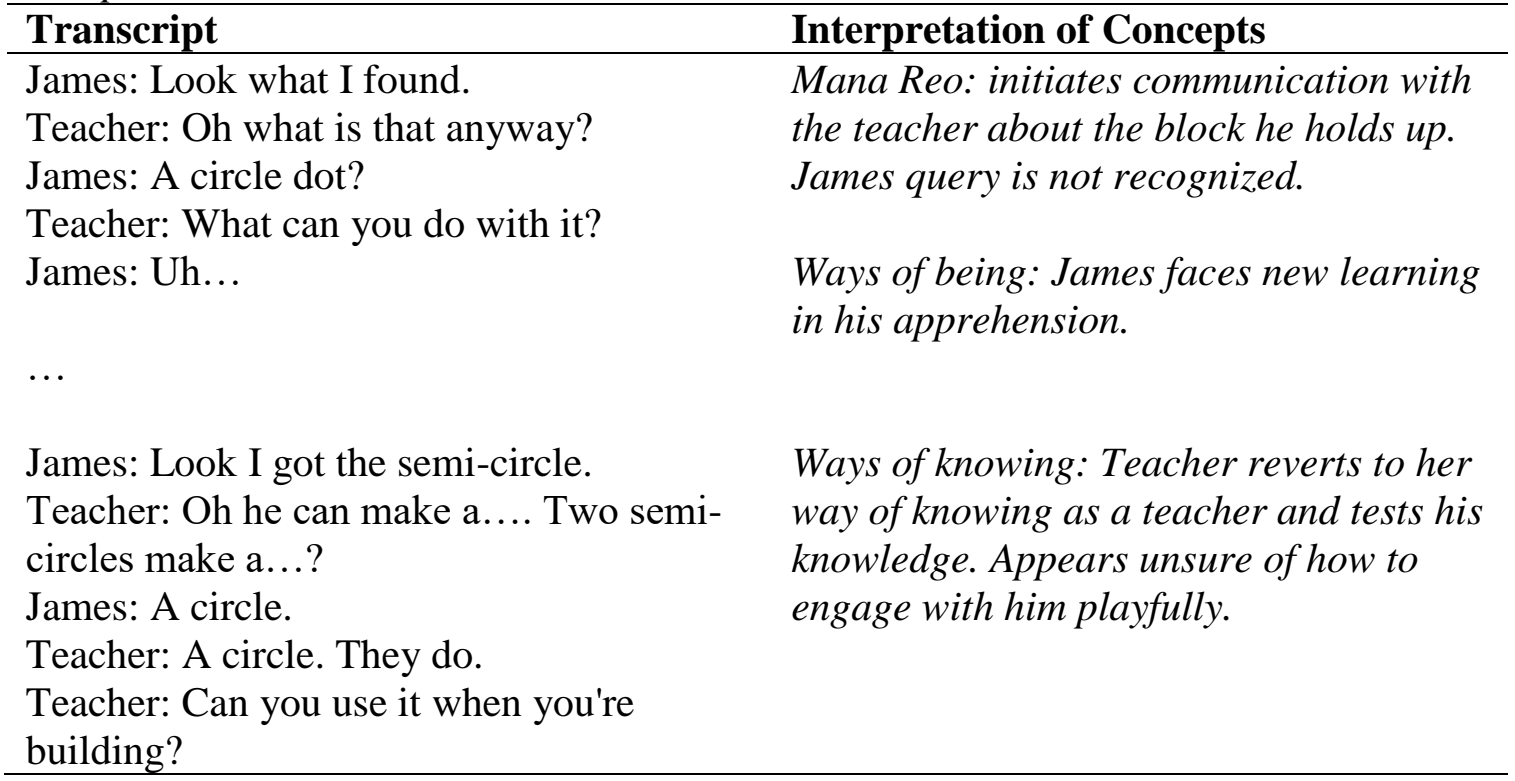

The explanatory notes that accompany the transcript indicate that James appears to observe and consider but not contribute ideas. It appears his language and thinking is less empowered than the other two children who engage readily with their own and the teacher's intentions for play and story building. Perhaps James is embodying a way of being reported that Indigenous children may tend to be silent as a sign of respect or reticent to take part, needing time to reflect before responding (Allen, 2014). Perhaps he is not communicating as readily because he is not feeling empowered. Of potential interest, James' efforts appear to be more centred on either periodically trying to engage the teacher with talk that either he perceives she wants to hear about the shapes and sizes of the blocks, or trying to engage her in a discussion about size and shapes because it interests him. Either way, his intent is not as readily responded to and consequently his language input is minimal throughout the duration of the play. This makes it challenging to be sure of his intentions, without knowing the child, and more so, his intentions appear to not align with the teacher's intentions related to story building. Certainly, while the teacher tries to engage him through prompting a question and answer exchange, it is not playful, and her attention is quickly diverted back to the two other more verbal children who invite her into their play and are therefore easier to respond to.

\section{Discussion}

From a sociocultural perspective play is the leading activity for learning and development and all learning is socially mediated and explored through real and imaginary experiences:

A child's play is not simply a reproduction of what he has experienced, but a creative reworking of the impressions he has acquired. He combines them and uses them to construct a new reality, one that conforms to his own needs and desires. (Vygotsky, 2004, p. 11) 
When we compare the empowerment of the three children in the transcript we see that the two more playful children, Cara and Alexandra, were more closely observed and listened to by the teacher as well as extending and building on their thinking with each other through play. As a result, their ideas and language were richer. Throughout most of the transcript we see these two children and their teacher come to understand new knowledge through playing and learning together, as they share their collective knowledge to create a complex narrative. The teacher gradually adjusts her teaching strategies and intentions, that is, ways of doing, and places herself within the play rather than as a facilitator of it. In doing so, she values the play first and foremost as the mechanism for more complex language and storytelling. Thus she empowers the children's language, play, and ideas through valuing their playful ways of knowing and being, and creates space for them to explore their specific interests and inquiries. As a result, richer language exchanges and plot lines are built on, queried, and negotiated. To this end the children and the teacher appear engaged in their play and the teacher's oral language goals are playfully incorporated into her prompting and elaborating from within the play, valuing the children's ideas and adding her concepts to the story rather than trying to explore them in isolation.

What the third child in this interaction brought to understandings or learned might only be revealed in later writing work in the classroom. James was less verbal and played largely alone on the periphery of this interaction. However, he too attempted to demonstrate ways to negotiate interactions with the teacher. Nevertheless, in contrast to the girls, the teacher's lack of responsiveness and James' lack of playfulness suggest his ways of knowing and being were not as well supported on this occasion. In short, these excerpts reveal the importance of play leading learning, and the value of a teacher being both playfully and culturally responsive within children's shared thinking space to empower their language and ideas, leading later to enriched storying which in turn can motivate writing.

Once again we stress our limitations; our interpretations of the teacher's and children's interactions are partial and subjective. Our aim is to share possibilities. The concept of whakapapa through layered ways of knowing, being, and doing, alongside Whakamana, Mana Reo, and funds of knowledge applied within a curriculum and assessment framework and cultural context are a means of seeing our way to working in more culturally and linguistically responsive ways, and of viewing the child as an empowered learner and communicator in their play and language.

Although the cultural emphases of Te Whāriki and Te Whatu Pōkeka are context specific to Aotearoa New Zealand, the underlying concepts and lenses for assessment may be considered across indigenous and diverse cultural settings. It remains teachers' responsibility to learn about and recognise the culturally specific embodied ways that Indigenous children bring to their play and learning. This then also becomes part of the teacher's ways of doing - to be open to learning and teaching with uncertainty, shifting the paradigm of Western educational discourse and coming to value the unfamiliar interpretations and possibilities that Indigenous children might bring. Creating and recognising space for indigenous embodied ways of knowing, being, and doing is the challenge for non-Indigenous educators of Indigenous children worldwide.

\section{Conclusion}


The NOW Play project promotes play-based teaching approaches for Indigenous children in Canada because of play's potential for rich language interactions. To add cultural and linguistic responsiveness to this understanding of play, we suggest it is important for all teachers to know about indigenous frameworks and/or culturally responsive ways of knowing, being, and doing that empower children's play and language. In particular, we argue that non-Indigenous teachers working with Indigenous children have a responsibility to understand and consider concepts relevant to local indigenous cultures. In the case of this article, we have illustrated concepts from culturally responsive frameworks for curriculum and assessment in Aotearoa New Zealand. Similar concepts from local cultures and indigenous groups might then be applied as ways of knowing, being, and doing in their contexts. In doing so, teachers may be better positioned pedagogically to respond meaningfully to children, and extend children's play and language in culturally relevant ways. Identifying with other perspectives or lenses is imperative if teachers and researchers are to work towards empowering local knowledge, and recognize and respond effectively to children's learning.

\section{Acknowledgements}

We thank Dr. Lesley Rameka and the reviewers of this article for their thoughtful and thought-provoking feedback on an earlier version. Ngā mihi nui.

\section{References}

Allen, W. (2014). Addressing Indigenous children's language development and assessment. Northern Oral Language and Writing Through Play Project, 1-5. December.

Bishop, R., Berryman, M., Wearmouth, J., Peter, M., \& Clapham, S. (2012). Professional development, changes in teacher practice and improvements in Indigenous students' educational performance: A case study from New Zealand. Teaching and Teacher Education, 28(5), 694-705. doi:10.1016/j.tate.2012.02.002

Carr, M. (2001). Assessment in early childhood settings: Learning stories. London, England: Paul Chapman.

Carr, M., \& Lee, W. (2012). Constructing learner identities in early childhood education. London, England: Sage.

Elsherief, H. (2016). Conceptualizing "culture" in relevant and/or sustaining pedagogy: Questions for teachers. Northern Oral Language and Writing Through Play Project, 1-3. March.

González, N., Moll, L. C., \& Amanti, C. (Eds.). (2005). Funds of knowledge: Theorizing practices in households, communities and classrooms. Mahwah, NJ: Lawrence Erlbaum.

Hedges, H. (2011). Rethinking SpongeBob and Ninja Turtles: Popular culture as funds of knowledge for curriculum co-construction. Australasian Journal of Early Childhood, 36(1), 25-29.

Hedges, H. (2015). Sophia's funds of knowledge: Theoretical and pedagogical insights, possibilities and dilemmas. International Journal of Early Years Education, 23(1), 83-96. doi:10.1080/09669760.2014.976609 
Ministry of Education. (1996). Te Whāriki: He whāriki mātauranga mō ngā mokopuna o Aotearoa: Early childhood curriculum. Wellington, New Zealand: Learning Media. Available from http://www.education.govt.nz/assets/Documents/EarlyChildhood/te-whariki.pdf

Ministry of Education. (2009). Te Whatu Pōkeka: Kaupapa Māori assessment for learning exemplars. Wellington, New Zealand: Learning Media. Available from https://education.govt.nz/assets/Documents/Early-Childhood/TeWhatuPokeka.pdf

Paris, D. (2012). Culturally sustaining pedagogy: A needed change in stance, terminology, and practice. Educational Researcher, 41(3), 9396. doi:10.3102/0013189X12441244

Peterson, S.S., McIntyre, L. J., \& Forsyth, D. (2016). Supporting young children's oral language and writing development: Teachers and early childhood educators' goals and practices. Australasian Journal of Early Childhood Education, 41(3), 11-19.

Rameka, L. K. (2007). Māori approaches to assessment. Canadian Journal of Native Education, 30(1), 126-144.

Rameka, L. K. (2012). Whakapapa: Culturally valid assessment in early childhood. Early Childhood Folio, 16(2), 33-37.

Reedy, T. (2013). Tōku Rangatiratanga nā te Mana-Mātauranga: 'Knowledge and power set me free'. In J. Nuttall (Ed.), Weaving Te Whāriki: Aotearoa New Zealand's early childhood curriculum document in theory and practice ( $2^{\text {nd }}$ ed., pp. 35-53). Wellington, New Zealand: NZCER.

Ritchie, J. R., \& Buzzelli, C. A. (2012). Te Whäriki: The early childhood curriculum of Aotearoa New Zealand. In N. File, J. J. Mueller, \& D. B. Wisneski (Eds.), Curriculum in Early Childhood Education: Re-examined, Rediscovered, Renewed (pp.146-159). New York, NY: Routledge.

Vygotsky, L. S. (2004). Imagination and creativity in childhood. Journal of Russian \& East European Psychology, 42(1), 7-97.

Walker, R. (2008). The philosophy of Te Whatu Pōkeka: Kaupapa Māori assessment and learning exemplars. The First Years: Nga Tau Tuatahi/New Zealand Journal of Infant and Toddler Education, 10(2), 5-10.

Weenie, A. (2008). Curricular theorizing from the periphery. Curriculum Inquiry, 38(5), 545-557. doi:10.1111/j.1467-873X.2008.00435.x

\section{Author Biographies}

Joanna Williamson is a $\mathrm{PhD}$. Candidate at the University of Auckland, New Zealand. Her research and teaching interests investigate young children's early language, literacy and concept development, teacher-child interactions, and early childhood curriculum and pedagogy.

Dr. Helen Hedges is an associate professor at the University of Auckland, New Zealand. Her research interests are in the areas of children's learning and development in the contexts of families and communities, teacher knowledge and professional learning, and early childhood curriculum and pedagogy. 